\title{
Revisiting the Elusive Hepatitis C Vaccine
}

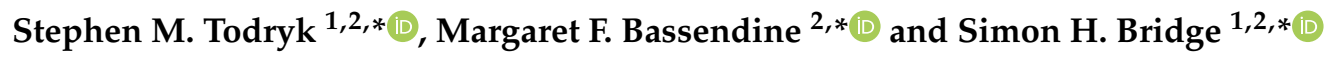 \\ 1 Faculty of Health \& Life Sciences, Northumbria University, Newcastle upon Tyne NE1 8ST, UK \\ 2 Translational \& Clinical Research Institute, The Medical School, Newcastle University, \\ Newcastle upon Tyne NE2 4HH, UK \\ * Correspondence: stephen.todryk@northumbria.ac.uk (S.M.T.); margaret.bassendine@newcastle.ac.uk (M.F.B.); \\ simon.bridge@northumbria.ac.uk (S.H.B.)
}

Citation: Todryk, S.M.; Bassendine, M.F.; Bridge, S.H. Revisiting the Elusive Hepatitis C Vaccine. Vaccines 2021, 9, 114. https://doi.org/ $10.3390 /$ vaccines 9020114

Received: 25 January 2021

Accepted: 27 January 2021

Published: 2 February 2021

Publisher's Note: MDPI stays neutral with regard to jurisdictional claims in published maps and institutional affiliations.

Copyright: (c) 2021 by the authors. Licensee MDPI, Basel, Switzerland. This article is an open access article distributed under the terms and conditions of the Creative Commons Attribution (CC BY) license (https:// creativecommons.org/licenses/by/ $4.0 /)$.
The impactful discovery and subsequent characterisation of hepatitis $\mathrm{C}$ virus $(\mathrm{HCV})$, an RNA virus of the flavivirus family, led to the awarding of the 2020 Nobel Prize in Physiology or Medicine to Harvey J. Alter, Michael Houghton and Charles M. Rice [1]. However, despite the significant advances recognised by this Nobel prize, an effective HCV vaccine remains elusive. The recent success of vaccines against SARS-CoV-2, developed with unprecedented speed, has shone a bright light on the vaccination process for protection against viral threats and may provide renewed impetus for the development of vaccines for other viruses. $\mathrm{HCV}$ infection remains a major global health problem as approximately three quarters of those infected develop chronic infection, leading to morbidity and mortality due to progressive liver fibrosis, cirrhosis and cancer. The World Health Organization (WHO) estimates that 71.1 million people are living with chronic $\mathrm{HCV}$, resulting in over 400,000 deaths every year. In 2016, the WHO adopted a global strategy with the aim of eliminating viral hepatitis as a public health problem, comprising targets to reduce new viral hepatitis infections by $90 \%$ and reduce deaths due to viral hepatitis by $65 \%$ by 2030 . Despite the use of highly effective antiviral drug combinations (direct-acting antivirals (DAAs)) and the adoption of treatment as prevention in resource-rich healthcare settings, there are an estimated 2-4 million new HCV infections annually, and the consensus is that the WHO target is unachievable without other measures, including an effective vaccine. A safe and affordable vaccine would particularly provide a realistic proposition in lowto middle-income countries with resource-constrained healthcare settings, which bear the brunt of chronic infections $(>80 \%)$. In addition, a vaccine would prevent infection or reinfection in high-risk groups in all countries. These groups comprise people who inject drugs, men who have sex with other men, prisoners, and people in receipt of poor medical and other procedures (i.e. unsafe practices including re-use of contaminated needles and syringes).

Several factors make it difficult to produce a vaccine against $\mathrm{HCV}$, including difficulty in propagating primary isolates of viruses in vitro or to test cell infection models, a paucity of accurate animal models, difficulty in testing efficacy in humans and genetic variants of the virus keeping viral antigens as a moving target for immune responses. A number of candidate HCV vaccines have, to date, been developed, reaching various stages of progress (examples in Table 1), although none has reached licensure and/or deployment. As for all vaccines, there are several features of vaccines that need to be considered in $\mathrm{HCV}$ vaccine design. These include the form in which the HCV antigens are delivered (recombinant protein, nucleic acid, peptides), delivery platform (recombinant virus, liposome, lipids/detergent, virus-like particles (VLPs)), co-administered immune adjuvants (bacterial-derived molecules, aluminium salts) and vaccination regimen (prime, boost, interval, target population). Most of the proteins that $\mathrm{HCV}$ possesses are potential antigen candidates that could be incorporated into a vaccine (Figure 1a), namely the core (C), envelope glycoproteins E1/E2, p7 and non-structural (NS2-5) proteins, and appropriate antigens must be selected. Structural proteins such as envelope glycoproteins are targets 
for neutralising antibodies (NAbs), whilst conserved non-structural (NS) proteins are considered better targets for T cell responses. HCV is a hepatotropic, enveloped, singlestranded, positive-polarity RNA virus that is not directly cytolytic or cytopathic, facilitating chronicity. Currently, HCV is classified into eight genotypes (GT1-8) and more than 86 subtypes, with GT1 being the most prevalent globally. The immune response against $\mathrm{HCV}$ is complex and is a double-edged sword, being capable of causing immunopathology (the cascade of inflammation, fibrosis, regeneration, cirrhosis and cancer) as well as potentially providing immune protection against the virus. This is in part due to the site of viral replication, the liver, possessing features that promote immune tolerance and immune downregulation (such as via regulatory $\mathrm{T}$ cells), which can suppress vital antiviral immune responses. $\mathrm{HCV}$ is able to utilise this site of relative immune privilege to evade immunity and has evolved mechanisms by which it can circumvent immunity, including generating antigenic escape mutants. The RNA-dependent RNA polymerase of $\mathrm{HCV}$ lacks proofreading capacity, meaning that many mutations and, hence, many antigenic variants (quasi-species) occur.

Table 1. Examples of vaccines in development for hepatitis $\mathrm{C}$ virus (HCV).

\begin{tabular}{|c|c|c|c|c|c|c|}
\hline Vaccine Type & Antigen & $\begin{array}{l}\text { Formulation/ } \\
\text { Vector }\end{array}$ & Phase & $\begin{array}{l}\text { Immunity } \\
\text { Generated }\end{array}$ & $\begin{array}{l}\text { Protection } \\
\text { Achieved }\end{array}$ & $\begin{array}{l}\text { Industrial Developer } \\
\text { (Previous/Current) }\end{array}$ \\
\hline 1. Subunit & $\begin{array}{l}\text { recE1E2 } \\
\text { heterodimer; E2; } \\
\text { Core }\end{array}$ & MF59/ISCOMATRIX & $\begin{array}{l}\text { Preclinical } \\
\text { Phase Ib }\end{array}$ & $\begin{array}{l}\text { Cross-genotype } \\
\text { NAbs, CD4+ T cells }\end{array}$ & In Chimpanzees & Chiron/Novartis/Italy \\
\hline $\begin{array}{l}\text { 2. Virus-like } \\
\text { particles (VLPs) }\end{array}$ & $\begin{array}{l}\text { E2; Core; } \\
\mathrm{HBV} / \mathrm{HCV}\end{array}$ & VLPs & Preclinical & NAbs, CD4+T cells & In Chimpanzees & None \\
\hline 3. Viral vector & NS3-5 & $\begin{array}{c}\text { ChAd3/MVA } \\
\text { Ad-associated } \\
\text { virus pVax-Ns5b }\end{array}$ & $\begin{array}{l}\text { Phase I/II } \\
\text { Preclinical }\end{array}$ & CD4+, CD8+ T cells & $\begin{array}{l}\text { In Chimpanzees, } \\
\text { not in humans }\end{array}$ & $\begin{array}{l}\text { Okairos/GSK/Oxford } \\
\text { Uni/NIH/NIAID }\end{array}$ \\
\hline 4. Peptide & p7/p6 MAP & IC-41 & Preclinical & T cells & NT & Copenhagen/SSI \\
\hline 5. DNA & $\begin{array}{l}\text { Core; E1; E2; } \\
\text { NS3-5A }\end{array}$ & $\begin{array}{c}\text { CIGB-230 } \\
\text { VGX-6150 } \\
\text { Ino-8000 }\end{array}$ & $\begin{array}{c}\text { Preclinical } \\
\text { Phase I } \\
\text { Phase I }\end{array}$ & CD4+, CD8+ T cells & $\begin{array}{l}\text { NT } \\
\text { NT } \\
\text { NT }\end{array}$ & $\begin{array}{c}\text { Chiron/Novartis } \\
\text { Cuba } \\
\text { Inovio }\end{array}$ \\
\hline 6. Nanoparticles & E2 & AddaVax & Preclinical & NAbs & NT & Scripps \\
\hline
\end{tabular}

Non-exhaustive list of vaccines in development for HCV. NT—not tested; NAbs—neutralising antibodies.

In addition, the rational design of any HCV vaccine must utilise advances in our understanding of the unique and dynamic composition of HCV particles circulating in the blood, recently confirmed by ultrastructural studies. HCV replicates mainly in the liver and hijacks one of its major roles, lipid metabolism, both inside and outside hepatocytes. In circulation, $\mathrm{HCV}$ is heterogenous both in size and density and exists in at least three, possibly interchangeable particles [2] (Figure 1b, i-iii):

i. Infectious HCV lipo-viral particles (LVPs) containing HCV core encapsulating RNA, $\mathrm{HCV}$ envelope proteins E1 and E2 and lipoproteins, including apolipoprotein E, which is not only present in higher copy numbers than E1/E2 but also facilitates viral entry via glycosaminoglycans, Low-Density Lipoprotein receptors, CD81 and Scavenger Receptor B1. The lipids in the HCV-LVPs serve to mask neutralising antibodies (NAbs) against HCV E1/E2.

ii. Sub-viral particles which do not contain core/RNA but are associated with HCV E1/E2. They significantly outnumber HCV-LVPs and may serve as a "decoy" for NAbs.

iii. Non-enveloped core particles which, again, may divert the immune response; they have been found to be a component of cryoprecipitable immune complexes in type II mixed cryoglobulinaemia. 
a.

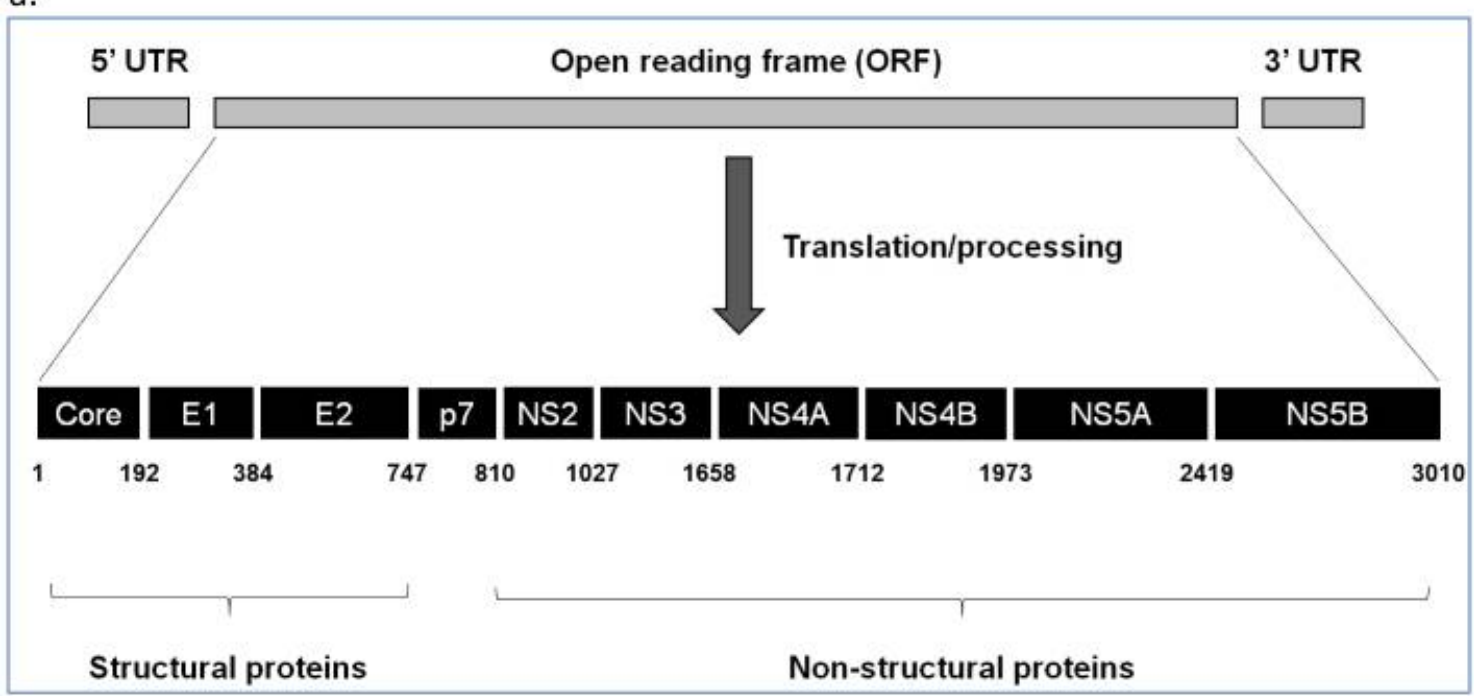

b.

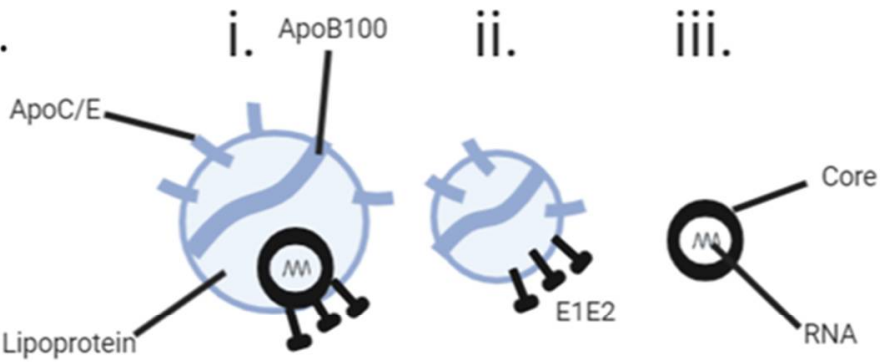

Vaccine

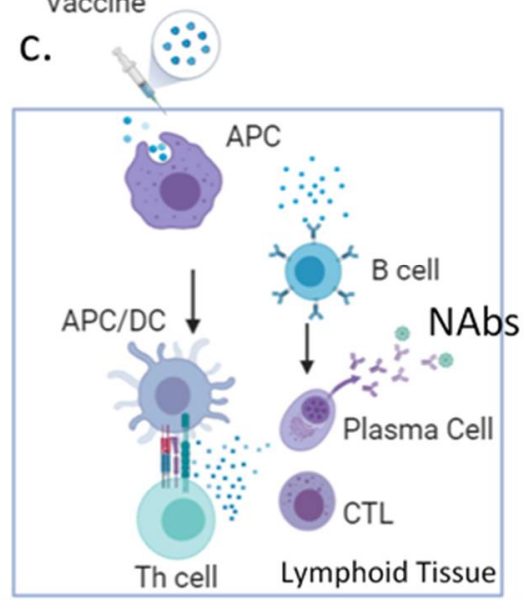

\section{Virus Particles}

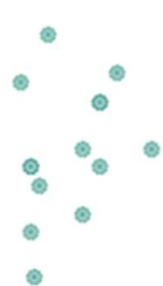

d.

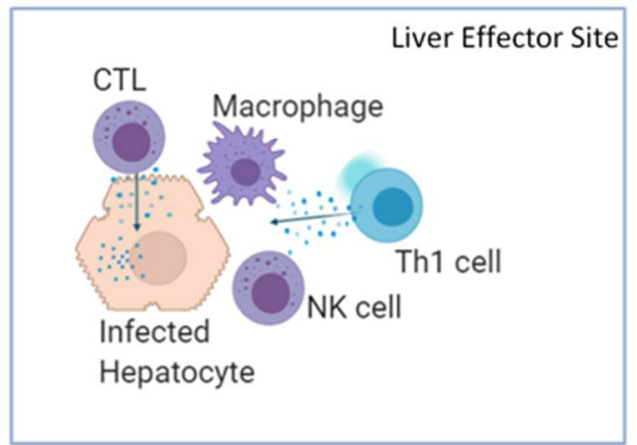

Figure 1. HCV proteins (antigens), dynamic composition of HCV particles, and indicative mechanisms (non-exhaustive) of vaccination and anti-viral immune protection. (a) The single stranded $9.6 \mathrm{~kb}$ RNA genome encodes a long open reading frame (ORF), which is flanked by 2 untranslated regions ( $5^{\prime}$ and $3^{\prime}$ UTR). The translated polyprotein is co-translationally and post-translationally processed by cellular and viral proteases. The numbers below the polyprotein denote the amino acid positions of the respective cleavage sites. (b) The unique and dynamic composition of the HCV particles circulating in the blood: (i) infectious HCV lipoviral particles (LVP), (ii) subviral particles, and (iii) non-enveloped core particles. (c) Potential vaccination process involving injection of vaccine, uptake by Antigen Presenting Cells (APCs particularly Dendritic Cells [DCs]), processing and presentation to T cells (Th cells and cytotoxic T cells (CTLs)), as well as viral recognition by $\mathrm{B}$ cells and the production of specific antibodies. (d) Potential effector mechanisms against HCV involve recognition of infected hepatocytes by CTLs and their secretion of cytolytic granules, recognition of antigen by Th1 cells and secretion of interferon (IFN) $\gamma$ that activates local NK cells and macrophages. Created with BioRender.com. 
First-line exposure and infection with HCV-LVPs leads to hepatocyte invasion by infectious particles, where viral RNA is sensed by Pattern Recognition Receptors (PRRs); TollLike Receptor( TLR)3, TLR7, retinoic-acid inducible gene I (RIG-I), melanoma differentiationassociated protein 5 (MDA5), NOD-like receptors (NLRs) and RIG-I-like receptors. (RLRs), leading to expression of type I and type III interferons, interleukin (IL)-1 $\beta$ and IL-18. These interferons inhibit viral replication and activate Natural Killer (NK) cells capable of killing infected hepatocytes via cytolytic pathways. Local antigen-presenting cells take up released viral antigens and are activated through interferons, IL-1 $\beta$ and IL-18 and via PRRs, and present viral peptide epitopes to $\mathrm{CD} 4^{+} \mathrm{T}$ cells via Major Histocompatibility Complex (MHC) class II to generate helper responses and to $\mathrm{CD} 8^{+} \mathrm{T}$ cells via MHC class I to generate cytotoxic T cell (CTL) responses. Whilst HCV-specific CD8 ${ }^{+}$CTLs directly kill infected cells via perforin/granzyme (Figure 1c,d), HCV-specific $\mathrm{CD} 4^{+}$helper $\mathrm{T}$ cells (Th) of the Th1 phenotype secrete interferon (IFN) $\gamma$, which inhibits viral replication and activates other cells such as NK cells and macrophages, causing local inflammation. Th cells are also critical not only to the generation and maintenance of robust functional CTLs but also for the activation and maintenance of B cells that recognise and secrete NAbs. These NAbs intercept viral particles, including sub-viral particles, and may prevent infectious LVPs from infecting hepatocytes. They tend to be directed against the E2 glycoprotein HVR1 region or the AR3 and AR4 regions, making them candidates for inclusion in vaccines. Evidence for the possibility of vaccine-induced immunity comes from the observation that spontaneous viral clearance occurs in $25 \%$ of those having primary infection and in $30-60 \%$ of those having one or more reinfections. Analysis of individuals who resolved their infection demonstrates immunity that is protective, comprising broadly cross-reactive (cross-genotype) NAbs, HCV-specific CTLs and Th1 cells that are proliferative and possess memory marker CD127 and lack programmed cell death protein (PD)-1. There is a particular emphasis on memory immune responses determining the strength and longevity of immune responses, and HCV vaccines aim to emulate or exceed this. Individuals with chronic $\mathrm{HCV}$ demonstrate exhausted and dysfunctional $\mathrm{T}$ cell immunity against $\mathrm{HCV}$, with $\mathrm{HCV}$-specific T cells expressing PD-1, and function is typically not restored following viral cure with DAAs. Exhaustion appears to be in part related to the very high viral (and hence antigenic) loads present. It has also become apparent that the homing of $\mathrm{T}$ cells to the liver and the establishment of tissue-resident memory $\mathrm{T}$ cells $\left(\mathrm{T}_{\mathrm{RM}}\right)$ that possess CD69, CD186 and CD103 are important for immunity in the liver. Priming of T cells locally to the liver may imprint these cells to remain there.

Several studies have shown that vaccines comprising the recombinant E1/E2 heterodimer together with adjuvants such as MF59 and ISCOMATRIX generated protective immunity in chimpanzees and, in humans elicited antibodies that neutralised HCV across genotypes [3]. A recent study in this journal by Ackache et al. (2019), entitled "Effect of Different Adjuvants on the Longevity and Strength of Humoral and Cellular Immune Responses to the HCV Envelope Glycoproteins" [4], compared lipid/saponin-based vaccine formulations used in licenced vaccines and a novel archaea-bacterial-derived adjuvant sulphated S-lactosylarchaeol (SLA), similar to monophosphoryl lipid A (MPL), in combination with recombinant E1/E2 heterodimer. Mice were immunised with three intramuscular inoculations (2-3 weeks apart) and immunity was successfully achieved as measured by antibody ELISA and pseudovirus inactivation (i.e., NAbs) and by T cell ELIspot and intracellular cytokine staining (for simultaneous IFN $\gamma$, TNF $\alpha$ and IL-2 [i.e., polyfunctionality]). Levels of immunity were maintained at 6 months post-vaccination. This is a similar immune profile to that seen in HCV-resolving humans.

Despite the initial promise of non-replicating viral-vector vaccines for HCV (Chimpanzee Adenovirus 3 (ChAd3) and Modified Vaccinia Ankara (MVA), both encoding genotype $1 \mathrm{~b}$ NS3-5A) given in a heterologous prime-boost regime showing protective immunity in chimpanzees [5] and immunity in human trials [6], protective immunity in high-risk individuals was not achieved [7], which has stalled progress of this approach. However, the success of such an approach, particularly in the context of SARS-CoV-2/COVID-19, 
suggests that it could be successful for HCV if the vaccination makeup and regimen can be optimised. It may be that the antigenic component needs to better match the HCV variants in circulation and that more studies of these heterogenous $\mathrm{HCV}$ particles are required in fasted individuals who resolve acute infection in parallel with characterising their immune response. Other studies have used perforin as an effective adjuvant for DNA vaccines [8] or suggest the use of virus-derived exosomes as vaccine components [9]. Further approaches involve adeno-associated viral vectors, which may enhance liver-homing of $T$ cells [10], and combination $\mathrm{HCV} / \mathrm{HBV}$ vaccines that utilise the ability of $\mathrm{HBV}$ to form immunogenic VLPs, as shown for licenced HBV vaccines [11]. Thus, similarly for SARS-CoV-2 and another flavivirus, Zika virus, a number of effective vaccines could enter trials and become available for $\mathrm{HCV}$, allowing at-risk groups or wider populations to be protected (from persistence if not from infection), which would reduce viral burden and transmission. The success of the SARS-CoV-2 RNA-based vaccines BNT162b1 (Pfizer and BioNTech) and mRNA-1273 (Moderna) with their demonstrated efficacy at preventing COVID-19 should provide new avenues to develop safe and affordable $\mathrm{HCV}$ vaccines adopting these exciting RNA-based approaches. Ultimately, not only must the immune system remember $\mathrm{HCV}$ in the correct way and scientists continue to develop $\mathrm{HCV}$ vaccines, but society must remember the need for a vaccine and recognise that it can be achieved if recognised as sufficiently important.

Author Contributions: S.M.T., M.F.B. and S.H.B. wrote the paper. All authors have read and agreed to the published version of the manuscript.

Funding: This research received no external funding.

Data Availability Statement: No data, not applicable.

Acknowledgments: The authors apologize to those whose work could not be cited due to space constraints.

Conflicts of Interest: The authors declare no conflict of interest.

\section{References}

1. Baumert, T.F. The Nobel Prize in Medicine 2020 for the Discovery of Hepatitis C Virus: Transforming Hepatology. J. Hepatol. 2020, 73, 1303-1305. [CrossRef] [PubMed]

2. Budkowska, A. Intriguing structure of the HCV particle. Gut 2017, 66, 1351-1352. [CrossRef] [PubMed]

3. Frey, S.E.; Houghton, M.; Coates, S.; Abrignani, S.; Chien, D.; Rosa, D.; Pileri, P.; Ray, R.; Di Bisceglie, A.M.; Rinella, P.; et al. Safety and immunogenicity of HCV E1E2 vaccine adjuvanted with MF59 administered to healthy adults. Vaccine 2010, 28, 6367-6373. [CrossRef] [PubMed]

4. $\quad$ Akache, B.; Deschatelets, L.; Harrison, B.A.; Dudani, R.; Stark, F.C.; Jia, Y.; Landi, A.; Law, J.L.M.; Logan, M.; Hockman, D.; et al. Effect of Different Adjuvants on the Longevity and Strength of Humoral and Cellular Immune Responses to the HCV Envelope Glycoproteins. Vaccines 2019, 7, 204. [CrossRef] [PubMed]

5. Folgori, A.; Capone, S.; Ruggeri, L.; Meola, A.; Sporeno, E.; Ercole, B.B.; Pezzanera, M.; Tafi, R.; Arcuri, M.; Fattori, E.; et al. A T-cell HCV vaccine eliciting effective immunity against heterologous virus chal-lenge in chimpanzees. Nat. Med. 2006, 12, 190-197. [CrossRef] [PubMed]

6. Swadling, L.; Capone, S.; Antrobus, R.D.; Brown, A.; Richardson, R.; Newell, E.W.; Halliday, J.; Kelly, C.; Bowen, D.; Fergusson, J.; et al. A human vaccine strategy based on chimpanzee adenoviral and MVA vectors that primes, boosts, and sustains functional HCV-specific T cell memory. Sci. Transl. Med. 2014, 6, 261ra153. [CrossRef] [PubMed]

7. Cox, A.L.; Page, K.; Melia, M.; Veenhuis, R.; Massaccesi, G.; Osburn, W.; Wagner, K.; Giudice, L.; Stein, E.; Asher, A.; et al. LB10. A Randomized, Double-Blind, Placebo-Controlled Efficacy Trial of a Vac-cine to Prevent Chronic Hepatitis C Virus Infection in an at-Risk Population. Open Forum Infect. Dis. 2019, 6 (Suppl. S2), S997. [CrossRef]

8. Shrestha, A.C.; Wijesundara, D.; Masavuli, M.G.; Addis, Z.; Gowans, E.J.; Grubor-Bauk, B. Cytolytic Perforin as an Adjuvant to Enhance the Immunogenicity of DNA Vaccines. Vaccines 2019, 7, 38. [CrossRef] [PubMed]

9. Urbanelli, L.; Buratta, S.; Tancini, B.; Sagini, K.; Delo, F.; Porcellati, S.; Emiliani, C. The Role of Extracellular Vesicles in Viral Infection and Transmission. Vaccines 2019, 7, 102. [CrossRef] [PubMed] 
10. Mekonnen, Z.A.; Grubor-Bauk, B.; English, K.; Leung, P.; Masavuli, M.G.; Shrestha, A.C.; Bertolino, P.; Bowen, D.G.; Lloyd, A.R.; Gowans, E.J.; et al. Single-Dose Vaccination with a Hepatotropic Adeno-associated Virus Efficiently Localizes T Cell Im-munity in the Liver with the Potential to Confer Rapid Protection against Hepatitis C Virus. J. Virol. 2019, 93, e00202-19. [CrossRef] [PubMed]

11. Czarnota, A.; Offersgaard, A.; Pihl, A.F.; Prentoe, J.; Bukh, J.; Gottwein, J.M.; Bieńkowska-Szewczyk, K.; Grzyb, K. Specific Antibodies Induced by Immunization with Hepatitis B Virus-Like Particles Carrying Hepatitis C Virus Envelope Glycoprotein 2 Epitopes Show Differential Neutralization Efficiency. Vaccines 2020, 8, 294. [CrossRef] [PubMed] 